See Article page 845 .

\section{Commentary: Rome was not built in a day...}

\author{
Thomas Schweiger, MD, PhD, and \\ Konrad Hoetzenecker, MD, PhD
}

Laryngotracheal-resection techniques belong to the most challenging airway procedures, with several factors contributing to their complexity: (1) the low incidence of laryngotracheal stenosis; (2) the delicate anatomical and functional characteristics of the laryngeal framework; (3) the required surgical expertise necessary to maintain the functional integrity of the larynx especially in extended resections; and (4) the devastating effects of complications.

Over the years, an increasing number of specialized referral centers that treat patients with laryngotracheal pathologies have developed. Starting with only around 5 laryngotracheal resections per year, the Rome group has steadily increased their case load over the years. In this issue of the Journal, Maurizi and colleagues ${ }^{1}$ report their summarized institutional experience covering a time period of almost 3 decades. The authors have to be congratulated on their excellent results in a meanwhile unique, large cohort of patients. With more than 40 laryngotracheal resections per year, the center belongs to the largest of its kind in Europe. A long-term treatment success-defined as permanent restitution of the airway and a good functional outcome-was achieved in $98.7 \%$ of patients. Once more, it was demonstrated that laryngotracheal resection provides a definite solution for patients, who had often gone through an odyssey of previously failed endoscopic treatment attempts. Moreover, the presented cohort shows that even stenoses involving the glottic level have meanwhile become amendable to surgical repair. Several novel reconstruction techniques for formerly unresectable stenosis have been reported in the literature..$^{2-4}$ Noteworthy, all

\footnotetext{
From the Department of Thoracic Surgery, Medical University of Vienna, Vienna, Austria.

Disclosures: The authors reported no conflicts of interest.

The Journal policy requires editors and reviewers to disclose conflicts of interest and to decline handling or reviewing manuscripts for which they may have a conflict of interest. The editors and reviewers of this article have no conflicts of interest.

Received for publication Dec 8, 2020; revisions received Dec 8, 2020; accepted for publication Dec 8, 2020; available ahead of print Dec 15, 2020.

Address for reprints: Konrad Hoetzenecker, MD, PhD, Department of Thoracic Surgery, Medical University Vienna, Waehringer Guertel 18-20, 1090 Vienna, Austria (E-mail: konrad.hoetzenecker@meduniwien.ac.at).

J Thorac Cardiovasc Surg 2021;161:853-4

0022-5223/\$36.00

Copyright (c) 2020 by The American Association for Thoracic Surgery

https://doi.org/10.1016/j.jtcvs.2020.12.024
}

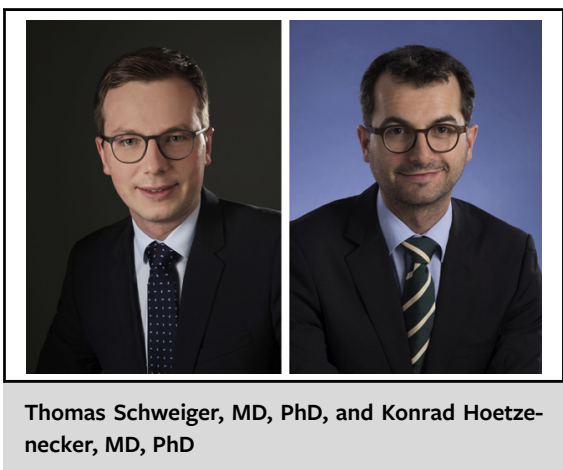

CENTRAL MESSAGE

A close collaboration of airway

centers and multi-institutional

outcome reporting is warranted

to further improve functional

results after laryngotracheal

surgery.

of these surgical innovations came from dedicated airway teams at high-volume centers.

An unquestioned disadvantage of laryngotracheal resection is its impact on voice quality. ${ }^{5}$ By disrupting the functional interplay between the cricoid and the thyroid cartilage, a reduced pitch range and a reduced fundamental frequency is found in most patients. Several efforts have been made to minimize the impact of cricotracheal resection on voice quality by preservation and reinsertion of the cricothyroid muscle, by preserving the lateral parts of the cricoid arch and by leaving the cricothyroid membrane intact. ${ }^{6,7}$

With the advent of well-established airway centers and the growing routine of these programs, we believe it is high time to join our forces and start reporting outcomes of laryngotracheal surgery in a multi-institutional manner. First efforts have been made by the North American Airway Collaborative, a consortium of 30 AngloAmerican centers. ${ }^{8}$ Recently, the European Society of Thoracic Surgeons and the Brazilian Society of Thoracic Surgeons have developed a joint database that aims to capture all technical details of laryngotracheal procedures and to provide a uniform reporting on functional outcomes.

Taking evidence of airway surgery to the next levelfrom single-center reports to multicenter databases-will need considerable effort, resources, and time. But after all, Rome was not built in a day... 


\section{References}

1. Maurizi G, Vanni C, Rendina EA, Ciccone AM, Ibrahim M, Andretti C, et al. Surgery for laryngotracheal stenosis: improved results. J Thorac Cardiovasc Surg. 2021;161:845-52.

2. Liberman M, Mathisen DJ. Tailored cricoplasty: an improved modification for reconstruction in subglottic tracheal stenosis. J Thorac Cardiovasc Surg. 2009; 137:573-8; discussion 578-9.

3. Ciccone AM, Vanni C, Maurizi G, D'Andrilli A, Korasidis S, Ibrahim M, et al. A novel technique for laryngotracheal reconstruction for idiopathic subglottic stenosis. Ann Thorac Surg. 2016;102:e469-71.

4. Hoetzenecker K, Schweiger T, Roesner I, Leonhard M, Marta G, DenkLinnert DM, et al. A modified technique of laryngotracheal reconstruction without the need for prolonged postoperative stenting. J Thorac Cardiovasc Surg. 2016; 152:1008-17.
5. Gelbard A, Anderson C, Berry LD, Amin MR, Benninger MS, Blumin $\mathrm{JH}$, et al. Comparative treatment outcomes for patients with idiopathic subglottic stenosis. JAMA Otolaryngol Head Neck Surg. 2020;146: 20-9.

6. Tanner K, Dromey C, Berardi ML, Mattei LM, Pierce JL, Wisco JJ, et al. Effects of voice-sparing cricotracheal resection on phonation in women. Laryngoscope. 2017; 127:2085-92.

7. Clunie GM, Roe JWG, Alexander C, Sandhu G, McGregor A. Voice and swallowing outcomes following airway reconstruction in adults: a systematic review. Laryngoscope. 2021;131:146-57.

8. Daniero JJ, Ekbom DC, Gelbard A, Akst LM, Hillel AT. Inaugural symposium on advanced surgical techniques in adult airway reconstruction: proceedings of the North American Airway Collaborative (NoAAC). JAMA Otolaryngol Head Neck Surg. 2017;143:609-13.
See Article page 845 .

\section{Commentary: Inching north up the airway: Thoracic surgeons as complete airway surgeons}

\author{
Cameron D. Wright, MD
}

Benign subglottic stenosis is most commonly due to prolonged intubation or idiopathic laryngotracheal stenosis. The 2 patient populations are different. Subglottic stenosis due to intubation usually has more involvement of the distal trachea, which can complicate repair because of the length of the involved stenosis, but often spares the subglottic space above the cricoid. Patients with idiopathic stenosis are almost always women with minimal involvement of the trachea, but their disease always extends for a variable amount of distance above the cricoid and can even involve the glottis. Both patient cohorts require resection of both the anterior cricoid and a variable amount of trachea to reconstruct their airway. Whereas a standard cervical trachea

From the Division of Thoracic Surgery, Massachusetts General Hospital, Boston, Mass.

Disclosures: Dr Wright reported consultant for BAYER for chronic thromboembolic pulmonary hypertension.

The Journal policy requires editors and reviewers to disclose conflicts of interest and to decline handling or reviewing manuscripts for which they may have a conflict of interest. The editors and reviewers of this article have no conflicts of interest

Received for publication Dec 4, 2020; revisions received Dec 4, 2020; accepted for publication Dec 5, 2020; available ahead of print Dec 13, 2020.

Address for reprints: Cameron D. Wright, MD, Division of Thoracic Surgery, Massachusetts General Hospital, Austen 7, Boston, MA 02114 (E-mail: cdright@mgh. harvard.edu).

J Thorac Cardiovasc Surg 2021;161:854-5

$0022-5223 / \$ 36.00$

Copyright (c) 2020 by The American Association for Thoracic Surgery

https://doi.org/10.1016/j.jtcvs.2020.12.021
Check for updates

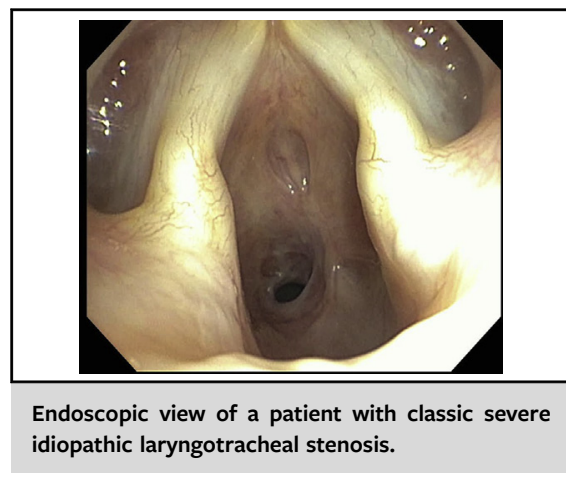

CENTRAL MESSAGE

Laryngotracheal resection for

subglottic stenosis in high-

volume centers offers patients a

single intervention with excellent

long-term results.

resection is a straightforward reproducible operation with excellent results when the larynx is involved, the difficulty is greater and the margin for success is less. The challenges to repair a subglottic stenosis include restoring a reasonable airway in the narrowest portion of the airway (the cricoid), a variable extension of disease above the cricoid into the subglottic space, the proximity of the vocal cords, and the tendency for the vocal cords and immediate subglottic submucosal space to become edematous and thus narrow the airway after operation. The repair of subglottic stenosis is not for the occasional surgeon.

Maurizi and colleagues ${ }^{1}$ report a retrospective series of laryngotracheal (cricotracheal) resections for subglottic stenosis from a high-volume center (average of 30 patients per 